THE EFFECT OF DISCOVERY LEARNING MODEL ON STUDENTS' LEARNING OUTCOMES ON THE THEME OF "DAERAH TEMPAT TINGGALKU"

\author{
Charianti Saragih $^{1}$, Reflina Sinaga $^{2}$, Saud Mahulae $^{3}$, Darinda Sofia Tanjung ${ }^{4}$ \\ 1,2,3,4 Universitas Katolik Santo Thomas, Medan, Indonesia \\ 1'chariantimunthe18@gmail.com, ${ }^{2}$ reflina_sinaga@ust.ac.id, ${ }^{3}$ mahulaesaud@gmail.com, ${ }^{4}$ darinda_tanjung@ust.ac.id
}

\title{
PENGARUH MODEL DISCOVERY LEARNING TERHADAP HASIL BELAJAR SISWA PADA TEMA DAERAH TEMPAT TINGGALKU
}

\begin{tabular}{|c|c|}
\hline ARTICLE INFO & ABSTRACT \\
\hline $\begin{array}{c}\text { Submitted: } \\
14 \text { September } 2020 \\
14^{\text {th }} \text { September } 2020\end{array}$ & $\begin{array}{l}\text { Abstract: This research aimed to analyze the effect of discovery learning model on students' learning } \\
\text { outcomes on the theme of "Daerah Tempat Tinggalku" at grade IV SD Negeri 091363 Huta Tinggir in } \\
\text { academic year 2019/2020. The population was all fourth grade students totaling } 50 \text { students. Samples } \\
\text { were taken by saturated sampling for as many as } 50 \text { students who were divided into two groups and } \\
\text { each group consisted of } 26 \text { and } 24 \text { students. The method used in this research was experimental method } \\
\text { in order to find out the effect of certain treatments on others conditions. The instrument in this research } \\
\text { was " } t \text { ", in the form of multiple choices. Then, the hypotheses were tested by using t test. Based on the } \\
\text { results of statistical calculation, it was revealed that after implementing discovery learning model, the } \\
\text { learning outcome of the students in experiment class was included in Good category (the average score } \\
=81.19) \text {. Meanwhile, the learning outcome of the students in control class did not improve significantly } \\
\text { from the KKM (the average score }=67.1 \text { ). Moreover, the result of the t-test resulted in the value of } t \\
\text { count }=9.790 \text { while } t \text { table }=2,055 \text {. This means that } t \text { count }>\text { t table; thus, Ho was rejected and Ha } \\
\text { was accepted. This research concluded that there was a significant influence of discovery learning } \\
\text { models on the students'learning outcomes at grade IV SD Negeri 091363 Huta Tinggir in the Academic } \\
\text { Year 2019/2020. }\end{array}$ \\
\hline
\end{tabular}

Keywords: learning outcomes, discovery learning model

Accepted:

29 Oktober 2020

$29^{\text {nd }}$ October 2020

Abstrak: Penelitian ini bertujuan untuk mengetahui pengaruh model discovery learning terhadap hasil belajar siswa pada tema daerah tempat tinggalku yang dilakukan di kelas IV SD Negeri 091363 Huta Tinggir Tahun Pembelajaran 2019/2020. Populasinya adalah seluruh siswa kelas IV yang berjumlah 50 siswa. Sampel diambil secara sampling jenuh yaitu sebanyak 50 siswa yang dibagi menjadi dua kelompok dan setiap kelompok berjumlah 26 dan 24 siswa. Metode yang digunakan dalam penelitian ini adalah metode eksperimen. Metode eksperimen yang dilakukan dalam penelitian ini untuk mencari pengaruh perlakuan tertentu terhadap yang lain dalam kondisi yang terkendalikan. Instrument yang digunakan adalah " $t$ ", dalam bentuk pilihan berganda. Pengujian hipotesis menggunakan uji " $t$ ".

Published:

25 Desember 2020

$25^{\text {th }}$ December 2020 Berdasarkan hasil pengolahan statistic menunjukan bahwa hasil belajar dengan mengunakan model discovery learning (kelas eksperimen) termasuk dalam kategori baik dengan rata-rata 81,19. Sedangkan hasil belajar tampa menggunakan model pembelajaran (kelas kontrol) belum terlalu menginkat dari KKM yang sudah ditetapkan dengan rata-rata 67,1. Dengan mengunakan uji-t diperoleh nilai $t_{\text {hitung }}=9,790$ sedangkan $t_{\text {tabel }} 2.055$ karena $t_{\text {hitung }}>t_{\text {tabel }}$ maka Ho ditolak dan Ha diterima Hal ini membuktikan bahwa terdapat pengaruh yang signifikan antara model discovery learning terhdap hasil belajar siswa kelas IV SD Negeri 091363 Huta Tinggir Tahun pembelajaran 2019/2020.

Kata kunci: hasil belajar, model discovery learning

\section{CITATION}

Saragih, C., Sinaga, R., Mahulae, D, S., \& Tanjung, D.S. (2020). The Effect of Discovery Learning Model on Students' Learning Outcomes on the Theme of "Daerah Tempat Tinggalku". Primary: Jurnal Pendidikan Guru Sekolah Dasar, 9(6), 819-827. DOI: http://dx.doi.org/10.33578/jpfkip.v9i6.8034. 


\section{PENDAHULUAN}

Sekolah dasar merupakan jenjang pendidikan yang sangat penting dan menentukan pribadi seseorang, karena pendidikan di sekolah dasar merupakan landasan pertama untuk menanamkan suatu konsep yang benar kepada anak. Diibaratkan dengan sebuah bangunan, pendidikan disekolah dasar merupakan pondasinya. Bangunan akan tetap kokoh apabila meliliki pondasi yang kuat. Begitu juga dengan halnya pendidikan di sekolah dasar, maka perlu direncanakan dan dilaksanakan dengan cermat agar kualitas pendidikan semakin baik oleh karena itu sejak dini harus disiapkan sumber daya manusia yang tangguh.

Guru memiliki tujuan agar peserta didik berhasil dalam setiap pembelajaran. Tujuan pembelajaran ini penting sekali untuk tolak ukur keberhasilan pembelajaran peseta didik. Tujuan pembelajaran dapat di capai dengan melibatkan peran guru sebagai fasilitator yang diharapkan memiliki cara atau model mengajar yang baik dan mampu memilih model pembelajaran yang tepat sesuai dengan konsep mata pelajaran yang akan disampaikan.Tujuan pendidikan tidak bisa lepas dari kurikulum sekolah.

Hal tersebut sejalan dengan Undangundang SISDIKNAS No. 20 Tahun 2003 pasal 1 (ayat 1) yang menyatakan bahwa pendidikan adalah usaha sadar dan terencana untuk mewujudkan suasana belajar dan proses belajar agar peserta didik secara aktif mengembangkan potensi dirinya untuk memiliki kekuatan spiritual keagamaan, pengendalian diri, kepripadian, kecerdasan, akhlak mulia, serta keterampilan yang diperlukan dirinya, masyarakat, bangsa dan Negara.

Dalam Kurikulum 2013 tidak hanya bidang kognitif saja yang perlukan dan dikembangkan tetapi sikap dan keterampilan siswa juga harus dikembangkan. Selain itu, Kurikulum 2013 lebih ditekankan pada dimensi pedagogik modern yaitu menggunakan pendekatan scientific, dalam pembelajarannya pendekatan scientific meliputi mengamati, menanya, menalar, mencoba, dan membentuk jejaring untuk semua mata pelajaran. Pendekatan scientific mengajak siswa untuk selalu aktif dan kreatif dalam setiap pembelajarannya dan menginspirasi siswa untuk berpikir secara logis, kritis dan analisis agar tepat untuk memahami, memecahkan masalah, dan mengaplikasikan materi pembelajaran.

Penerapan pendekatan scientific dalam model pembelajaran yang diterapkan dalam Kurikulum 2013 yaitu Model Discovery Learning atau model pembelajaran penemuan. Model pembelajaran Discovery Learning menggunakan beberapa langkah pembelajaran, yaitu persiapan, pelaksanaan, dan penilaian.

Pembelajaran dapat menjadi bermakna karena berbagai faktor, salah satunya pengaruh model pembelajaran yang digunakan oleh guru mampu menunjang proses belajar. Model pembelajaran merupakan salah satu aspek yang penting dalam proses pembelajaran. Pemilihan model pembelajaran yang tepat dapat membantu guru untuk meningkatkan hasil belajar dan menciptakan suasana kelas yang lebih aktif. Salah satu model pembelajaran yang erat hubungannya yaitu model discovery learning ,Erwin Widiasworo(2018:161) menyatakan pembelajaran discovery learning merupakan model pembelajaran yang didefinisikan sebagai pembelajaran dalam bentuk finalnya,tetapi diharapkan peserta didik mengorganisasikan sendiri.

Penelitian ini sependapat dengan Shelfa Salsabilla yang berjudul Pengaruh Model Discovery Leaerning Terhadap Hasil Belajar Tematik Peserta Didik Dikelas IV SD Negeri 2 Kedamaian Bandar Lampung. Bahwa dalam sekolah dasar itu guru harus kreatif dalam memilih model pembelajaran yang sesuai dengan materi pembelajaran, sesuai dengan kemampuan peserta didik, dan sesuai dengan tujuan pembelajaran ,harus lebih menyenangkan dapat membangkitkan keaktifan siswa dalam proses pembelajaran. Sehingga nilai hasil peserta didik menjadi meningkat dari nilai yang sebelumnya.

Berdasarkan hasil observasi penelitian yang dilakukan melalui pembicaraan singkat dengan guru kelas IV SD Negeri 091363 Huta Tinggir, bahwa sekolah sudah mengikuti pembelajaran tematik, akan tetapi dalam 
penerapannya guru masih terfokus dalam mata pelajaran. Seolah-olah masih terjadi pemisahan antara mata pelajaran yang satu dengan pelajaran yang lain. Oleh karena itu, pada penelitian ini peneliti mempokuskan pada tema daerah tempat tinggalku dengan pembelajaran 5 yang terdiri dari tiga mata pelajaran yaitu Bahasa Indonesia, SBDP dan Pkn. Alasan memilih tema tersebut adalah hasil observasi peneliti menemukan bahwa nilai kelas IV belum memenuhi KKM diatas 70 rendahnya hasil belajar siswa dibuktikan pada hasil tahun ajaran 2019/2020 sebagai berikut.

Tabel 1. Data Nilai Tema 8 (Daerah Temapat Tinggalku) subtema 2 (Keunikan Daerah Tempat Tinggalku) kelas IV SD Negeri 091363 Huta Tinggir Tahun Pembelajaran 2019/2020.

\begin{tabular}{|c|c|c|c|c|c|c|}
\hline Kelas & $\begin{array}{l}\text { Jumlah } \\
\text { Siswa }\end{array}$ & Nilai & KKM & $\begin{array}{l}\text { Jumlah } \\
\text { Ketuntasan }\end{array}$ & $\begin{array}{l}\text { Presentasi } \\
\text { ketuntasan }\end{array}$ & Keterangan \\
\hline IV & 26 & $\begin{array}{l}>70 \\
<70\end{array}$ & 70 & $\begin{array}{l}6 \text { Orang } \\
20 \text { Orang } \\
26 \text { orang }\end{array}$ & $\begin{array}{l}23.07 \% \\
76.92 \% \\
100 \%\end{array}$ & $\begin{array}{l}\text { Tuntas } \\
\text { Tidak Tuntas }\end{array}$ \\
\hline
\end{tabular}

Sumber : Wali kelas IV semester ganjil SD Negeri 091363 Huta Tinggir Tahun pembelajaran 2019/2020

Berdasarkan tabel 1 di atas dapat diketahui bahwa hasil nilai yang diproleh peserta didik dapat memenuhi tingkat keberhasilan maksimal, hal ini dikarenakan yang memproleh nilai sesuai KKM sekitar 6 orang $(23.07 \%)$ sementara yang diproleh nilai yang dibawah KKM sebanyak 20 orang (76.92\%). Melihat dari kenyataan yang telah dipaparkan diatas maka perlu diakan perbaikan pembelajaran.

Hasil penelitian Shelfa Salsabilla yang berjudul "pengaruh Model Discovery Learning

\section{KAJIAN TEORETIS}

Model pembelajaran discovery learning merupakan salah satu model pembelajaran penemuan yang dapat mendorong siswa untuk belajar aktif dalam pembelajaran penemuan, guru hannya mendorong siswa untuk memiliki pengalaman dalam melakukan percobaan yang memungkinkan peserta didik untuk memahami materi yang dia pelajari sendiri. Model Pembelajaran Discovery Learning adalah model pembelajaran yang mengatur sedemikian rupa sehingga siswa memproleh pengetahuan yang belum diketahuinya, baik sebagian maupun seluruhnya ditemukan sendiri.

Menurut Jerome Bruner (Fitri, 2015:3) "Model pembelajaran yang dirancang dengan tujuan untuk membantu siswa mengembangkan kemampuan berfikir dan mengembangkan kemempuan dalam memecahkan masalah kehidupan sehari-hari, dan menekankan
Terhadap Hasil Belajar Tematik Peseta Didik dikelas IV SD Negeri 2 Kedamaian Bandar Lampung". Bahwa dalam sekolah dasar itu guru harus kreatif dalam memilih model pembelajaran yang sesuai dengan materi pembelajaran, sesuai dengan kemampuan peserta didik, dan sesuai dengan tujuan pembelajaran, harus lebih meyenangkan dapat membangkitkan keaktifan siswa dalam proses pembelajaran sehingga nilai hasil peserta didik menjadi meningkat dari nilai yang sebelumnya.

pentingnya membantu siswa untuk memahami struktur atau ide-ide kunci suatu disiplin ilmu,kebutuhan akan keterlibatan aktif siswa dalam proses belajar dan keyakinan bahwa pelajaran sejati terjadi melalui penemuan pribadi”.

Pendapat Widiasworo (2018:161) discovery learning merupakan model pembelajaran yang menekankan peserta didik untuk menemukan sendiri konsep pengetahuannya. Dalam proses menemukan, peserta didik dibimbing untuk melakukan serangkaian tahap pembelajran mulai dari mengamati hingga mengorganisasikan hasil penemuannya menjadi suatu konsep pengetahuan sendiri dan bertambahnya pengetahuan yang dimiliki siswa itu sendiri.

Berdasarkan beberapa pendapat para ahli diatas dapat disimpulkan bahwa model pembelajaran Discovery learning adalah model belajar yang menekankan peserta didik untuk 


\section{PRIMARY : JURNAL PENDIDIKAN GURU SEKOLAH DASAR \\ VOLUME 9 NOMOR 6 DESEMBER 2020}

ISSN: 2303-1514 | E-ISSN: 2598-5949

Jurnal Pendidikan Guru Sekolah Dasar

DOI : http://dx.doi.org/10.33578/jpfkip.v9i6.8034

https://primary.ejournal.unri.ac.id/index.php/JPFKIP

menemukan sendiri konsep pengetahuannya. Proses belajar dapat menentukan suatu pendidikan apabila dapat menyusun terlebih dahulu beragam materi yang akan disampaiakan, dalam konteks ini, menemukan sesuatu berarti peserta didik

\section{METODE PENELITIAN}

Teknik pengumpulan data adalah cara-cara yang digunkan untuk mengumpulkan data. Teknik pengumpulan data yang digunakan dalam penelitian ini yaitu observasi, teknik tes dan studi dokumentasi.

1. Observasi

Dilakukan untuk mengetahui kondisi lingkungan belajar siswa, melihat aktivitas pembelajaran guru dan siswa khususnya mengenai model pembelajaran discovery learning yang diterapkan pada kelompok eksperimen.

2. Teknik Tes

Tes adalah seperangkat rangsangan yang diberikan kepada seseorang dengan maksud untuk mendapatkan jawaban yang dijadikan dasar bagi penetapan skor angka. Tes digunakan untuk mengukur hasil belajar siswa terhadap materi yang dipelajari. Tes yang digunakan kepada peserta didik berbentuk soal pilihan ganda, berupa tes tertulis.

Instrument yang digunakan dalam penelitian ini berupa tes soal yang dibuat sendiri oleh peneliti. Menurut Sugiyono (2017:305) instrumen penelitian yaitu penelitian yang berkenaan dengan validitas dan realibitas instrument dan kuantitas pengumpulan data berkenaan ketetapan cara-cara yang digunakan untuk mengumpulkan data. Maka dalam penelitian ini peneliti mengunakan tes sebagai instrument peneliti. Dengan demikian penggunaan instrument yaitu untuk mencari informasi yang lengkap mengenai suatu masalah fenomena alam maupun sosial. Instrument yang baik apabila memenuhi syarat sebagi instrument yang standar, intrumen standar apabila intrumen itu valid atau tetap. Kualitas intrumen penelitian berkenaan dengan validitasi dan relibitasi.

Intrumen tes yang digunakan dalam penelitian ini adalah tes hasil belajar tema daerah tempat tinggalku yakni pretest dan prottest. Pretest mengenal, menghayati, dan memahami sesuatu yang belum pernah diketahui sebelumnya agar dapat dijadikan bahan pelajaran dalam menciptakan inovasi pembelajaran yang lebih menggairahkan .

diberikan kepada sampel sebelum perlakuan (treatment) dengan tujuan untuk mengetahui hasil awal siswa sedangkan posttest diberikan setelah perlakuan (treatment) dengan tujuan untuk mengetahui hasil belajar siswa. Tes hasil belajar siswa disusun dalam bentuk tes objektif pilihan berganda dengan empat pilihan jawaban (a,b,c dan d). butiran tes tersebut dirancang melalui tiga ranah kognitif menurut Taksonomi Bloom yaitu aspek pengetahuan (C1), pemahaman (C2), dan penerapan (C3) dan (C4) menganalissis dengan jumlah soal yang digunakan peneliti melakukan analisis instrument tes secara kuantitatif. Untuk mengetahui validitas dan realibitas dari soal tersebut maka digunakan rumus sebagai berikut.

\section{Uji Validitas}

Uji validitas adalah pengujian suatu alat ukur yang digunakan untuk mengukur variabel yang ada. Menurut Arikunto (2017:211) menyatakan bahwa validitas adalah suatu ukuran yang menunjukkan tingkat kevalitan suatu instrument. Jika suatu instrument valid maka instrument tersebut memiliki validitas yang tinggi. Suatu instrument dikatakan valid apabila mampu mengukur apa yang diharapkan oleh peneliti, dan data dapat memperjelas variabel yang diteliti dengan tepat. Dalam penelitian ini, validitas tes diukur dengan korelasi Product Moment: cara yang digunakan untuk mengetahui tingkat validitas instrument pada penelitian ini adalah mengunakan rumus korelasi, Menurut Sudjana (2016:144) sebagai berikut:

Keterangan:

$$
r_{x y}=\frac{N \sum x y-\left(\sum x\right)\left(\sum y\right)}{\left(N \sum x^{2}-\left(\sum x^{2}\right)\right\}\left\{\left(N \sum Y^{\left.2-\left(\sum Y^{2}\right)\right\}}\right.\right.}
$$

$r_{x y}=$ koefisien korelasi antara $\mathrm{x}$ dan $\mathrm{y}$

$\mathrm{N} \quad=$ banyaknya subjek pengikut 
$\sum \mathrm{xy}=$ Jumlah hasil perkalian antara skor " $\mathrm{X}$ " dan "Y"

$\mathrm{X}=$ nilai pembanding

$\mathrm{Y} \quad=$ nilai dari instrument yang akan dicari validitasnya

Untuk menentukan instrument valid atau tidaknya maka diperlukan bantuan program SPSS Ver 22.0 adalah sebagai berikut.

1. Jikar $_{\text {hitung }} \geq \mathrm{r}_{\text {tabel }}$ tarafsignifikan $0.5 \%$, maka instrument tersebutdikatakan valid.

2. Jikar $_{\text {hitung }} \leq \mathrm{r}_{\text {tabel }}$ dengantarafsignifikan $0.5 \%$, maka instrument tersebutdikatakantidak valid.

Realibilitas/keterandalan ialah indeks yang menunjukkan sejauh mana alat ukur yang dipercaya. Menurut Wardani (2016:531) bahwa alat ukur yang baik adalah alat ukur yang mempunyai reliabilitas yang tinggi artinya setiap kali alat ukur digunakan untuk mengukur hal yang sama dan hasil pengukurannya tetap. Raliabilitas akan menurunkan ukuran suatu benda, kualitas butir soal pun ada yang reliable da nada yang tidak. Pada penelitian ini untuk menunjukkan reliabitas tes digunakan rumus K-R 20. Adapun rumus menurut Arikunto (2012:115) sebagai berikut.

$$
r_{11}=\left(\frac{N}{n-1}\right)\left(\frac{s_{t}^{2}-\sum p q}{s_{t}^{2}}\right) \text { (Purwanto,2017:169) }
$$

Sebelum menghitung reliabilitas tes, terlebih dahulu dicari varians total dengan menggunakan persamaan sebagai berikut:

$s_{t}^{2}=\frac{\sum y^{2 \frac{\left(\sum y\right)^{2}}{N}}}{N}$

Keterangan :

$r_{11}=$ Reliabilitas yang dicari

$\mathrm{n}=$ Jumlah butir soal

$s_{t}^{2} \quad=$ Varians skor total

$\sum \mathrm{pq}=$ Jumlah varians skor tiap-tiap item

$\mathrm{P} \quad=$ Proporsi skor yang diperoleh

$\mathrm{Q}=$ Proporsi skor maksimal dikurangi skor yang diperoleh

Untuk menafsirkan arti suatu koefisien reliabilitas dapat digunakan pedoman sebagai berikut:

$0.00 \leq r_{11} \leq 0.40 \quad:$ reliabilitas rendah
$0.41 \leq r_{11} \leq 0.70$

$0.71 \leq r_{11} \leq 0.90$

$0.91 \leq r_{11} \leq 1.00$

Uji normalitas dilakukan untuk mengetahui apakah data yang digunakan dalam penelitian berdistribusi normal atau tidak. Untuk mengetahui data distribusi normal atau tidak, peneliti menggunakan analisa kolmogrov-smirnov dengan bantuan program spss versi 22.0. Hasil perhitungan menunjukkan data berdistribusi normal jika nilai Asymp. Sign lebih besar dari 0.05> 0.05. Sebaliknya, jika nilai Asymp.Sign. Kurang darisama dengan $0.05<0.05$ maka data dapat dikatakan tidak berdistribusi normal. Nilai Asymp. Sign ini menguji signifikasi pada hasil perhitungan Kolmogav-Smirnov test. Uji normalitas data yang dilakukan dalam penelitian ini menggunakan uji lillliefors, Sudjana (2017:466).

a. Data hasil belajar $X_{1}, X_{2}, \ldots \ldots \ldots, X_{n}$ dijadikan angka baku $Z_{1}, Z_{2}, Z_{n}$

$$
Z_{1}=\frac{x i-x}{S D}
$$

b. Untuk setiap bilangan baku ini dengan menggunakan distribusi normal dihitung peluang $\mathrm{F}\left(Z_{i}\right)=\mathrm{P}\left(\mathrm{Z} \geq Z_{i}\right)$

c. Selanjutnya dihitung proporsi $Z_{1}, Z_{2}, \ldots \ldots, Z_{n}$ yang lebih kecil atau sama dengan $Z_{i}$. Jika proporsi itu menyatakan dengan $\mathrm{S}\left(Z_{i}\right)$, maka

$$
\mathrm{S}\left(Z_{i}\right)=\frac{\text { banyaknya } Z 1, Z 2, \ldots . . . Z n \text { yang } \leq Z i}{n}
$$

d. Menghitung selisih $\mathrm{F}\left(Z_{1}\right)-\mathrm{S}\left(Z_{1}\right)$ kemudian ditentukan harga mutlaknya.

e. Mengambil harga mutlak yang tersebar $\left(L_{o}\right)$ untuk menerima atau menolak hipotesis, kemudian membandingkan $L_{o}$ dengan nilai kritis yang diambil dari daftar untuk taraf nyata $\infty=0.05$.

Dengan criteria :

Jika $L_{\text {hitung }}<L_{\text {tabel }}$ maka sampel tidak berdistribusi normal.

Jika $L_{\text {hitung }}>L_{\text {tabel }}$ maka sampel berdistribusi normal.

\section{UjiHomogenitas}

Pengujian homogenitas dilakukan untuk mengetahui apakah data mempunyai varians yang sama atau tidak menurut Sudjana, (2017:249). 
Untuk menguji homogenitas data suatu populasi digunakan uji kesamaan varians. Populasi dengan varians yang sama besar dinamakna populasi dengan varians yang homogeny. Sedangkan populasi dengan varians yang tidak sama dinamakan populasi heterogen. Pengujian homogenitas dilakukan dengan rumus homogenetis korelasi product moment. Dengan berbantukan program SPSS Versi 22.0 uji homogenetis yang digunakan adalah cara varians terbesar dibandingkan dengan varians terkecil dengan langkah-langkah sebagai berikut :

1. Menentukan taraf signifikan, dalam penelitian ini taraf signifikasikannya adalah $\infty=0.05$.

2.Cari $F_{\text {hitung }}$ dengan rumus :

$F_{\text {hitung }}=\frac{\text { Varians } \text { Terbesar }}{\text { Varians Terkecil }}$ atau $\mathrm{F}=\frac{S 1^{2}}{S 2^{2}}$

Keterangan :

$S 1^{2}=$ varian dari kelompok yang terbesar

$S 2^{2}=$ varian dari kelompok terkecil

Kriteria Penelitian

Jika $F_{\text {hitung }}>F_{\text {tabel }}$ maka sampel mempunyai varians yang sama.

Jika $F_{\text {hitung }}<F_{\text {tabel }}$ maka sampel tidak mempunyai varians yang sama.

\section{Teknik Pengolahan (Analisis) Data}

Menurut Sugiyono (2017:308) teknik pengumpulan data merupakan langkah paling utama dalam penelitian karena tujuan utama dari penelitian adalah mendapatkan data. Tanpa mengetahui teknik pengumpulan data, maka peneliti tidak akan mendapatkan data yang memenuhi standar data yang ditetapkan. Data yang sudah dikumpul akan dianalisis untuk menemukan pembuktian dari rumusan pertanyaan. Pengumpulan data dapat dilakukan dalam berbagai setting, berbagai sumber, dan berbagai cara. Bila dilihat dari settingnya, data dapat dikumpulkan pada setting alamiah (natural setting) pada laboratorium dengan metode eksperimen di sekolah dengan berbagai responden pada suatu diskusi,dan lain-lain. Setelah memperoleh data analisis tersebut dapat dilakukan dengan langkahlangkah sebagai berikut:

1. Mengoreksi atau memeriksa kertas jawaban siswa.

2. Menabulasi skor post test (X).
3. Mencari mean hasil post test dengan rumus yang dinyatakan oleh Sudijono (2014:159).

$M_{x}=\frac{\sum f x}{N}$

Keterangan :

$M_{x}=$ Rata-rata

$\sum f x=$ Jumlah hasil dari penelitian masingmasing interval dengan frekuensinya.

$$
\mathrm{N}=\text { Jumlah }
$$

4. Mencari standar deviasi dengan rumus :

$\mathrm{SD}=\sqrt{\frac{\sum X^{2}}{N}} \quad$ (Sudijono, 2014:159)

$\mathrm{SD}=$ Standar Deviasi

$\sum X^{2}=$ Number of Cases

$\mathrm{N}=$ Jumlah

5. Menghitung standar error dari variable hasil post test dengan menggunakan rumus :

$S E_{M}=\frac{S D}{\sqrt{N-1}}$

Keterangan :

$\mathrm{SD}=$ Standar Deviasi

$S E_{M}=$ Standar Error

$\mathrm{N}$ = Jumlah Sampel

\section{Uji Regresi Linier Sederhana}

Analisis regresi linier sederhana adalah hubungan secara linier antara satu variabel independen $(\mathrm{X})$ dengan variabel dependen $(\mathrm{Y})$. analisis ini untuk mengetahui arah hubungan antara variabel independen dengan variabel dependen apakah positif atau negative dan untuk memprediksi nilai dari variabel dependen apabila nilai variabel independen mengalami kenaikan atau penurunan. Data yang digunakan biasanya berskala interval atau rasio menurut Kurniawan (2016:63) dengan rumus regresi linear sederhana sebagai berikut :

$$
\grave{Y}=\mathrm{a}+\mathrm{bX}
$$

Keterangan :

$\grave{Y}=$ variabel dependen (nilai yang diprediksi)

$\mathrm{X}=$ variabel independen

$\mathrm{a}=$ Konstanta (nilai $\grave{Y}$ apabila $\mathrm{X}=0$ )

$\mathrm{b}=$ Koefisien regresi (nilai peningkatan ataupun penurunan)

\section{Uji Hipotesis}

Uji hipotesis dilakukan untuk mengetahui kebenaran hipotesis itu sendiri. Untuk menguji hipotesis dalam penelitiitu yang digunakan adalah 
uji satu pihak. Dengan taraf $\infty=0.05$. dengan rumus uji signifikasi korelasi product moment. Dengan berbantukan program SPSS Versi 23.0.

Rumus yang digunakan dalam Uji-t adalah sebagai berikut :

1. Jika data berasal dari populasi yang homogen, maka digunakan rumus uji-t :

$$
\mathrm{t}=\frac{X_{1-X_{2}}}{s \sqrt{\frac{1}{n_{1}}+\frac{1}{n_{2}}}} \text { dengan } S^{2}=\frac{\left(n_{1-1}\right) S_{2+\left(n_{1-1}\right) S_{2}^{1}}^{1}}{n_{1+n_{2}}-2}
$$

Sudjana (2017:239)

2. Jika data berasal dari populasi yang tidak homogeni, maka digunakan rumus uji-t yaitu :

\section{HASIL DAN PEMBAHASAN}

Jika diamati dari koefisien variabel, penelitian ini dapat dinyatakan bahwa variabel model discovery learning lebih tinggi dari pada siswa yang mendapatkan pembelajaran konvensional. Hasil analisis yang diperoleh memberikan gambaran bahwa ternyata model discovery learning berpengaruh terhadap hasil belajar pada tema 8 subtema 2 pembelajaran 1 dan pembelajaran 2.

Berdasarkan hasil penelitian maka diperoleh temuan peneliti yang sebagai berikut:

1. Untuk mengetahui kemampuan awal siswa penelitian ini mengunakan pre test di kelas control dan di kelas eksperimen dengan jumlah soal masing-masing sebanyak 33 butir soal pilihan berganda, pre test dari control dengan rata-rata 47.583 dan pre tes eksperimen dengan rata-rata 53.461. Dari rata-rata tersebut dapat dilihat bahwa kemampuan pre test di kelas control dan kelas ekperimen masih di bawah KKM atau masih rendah. Kemudian setelah diberikan treatment atau perlakuan model discovery learning di kelas ekperimen memiliki rata-rata 81.5 sementara di kelas control dengan model konvensional memiliki rata-rata 67.1.

2. Hasil uji normalitas dengan taraf Sig, $\alpha=0.05$ dengan kriteria pengujian normalitas yaitu $\mathrm{L}_{\text {hitung }}>\mathrm{L}_{\text {tabel }}$ maka sampel berdistribusi normal. Berdasarkan hasil uji normalitas diketahui bahwa nilai signifikan A siymp. Sig (2 tailed) sebesar 0.118 lebih besar dari 0.05. Maka sesuai dengan dasar pengambilan keputusan

$$
\mathrm{t}=\frac{X_{1}-X_{2}}{\sqrt{\frac{s_{2}^{1}}{n_{1}}-\frac{s_{2}^{1}}{n_{2}}}} \quad \text { Sudjana }(2017: 245)
$$

$\mathrm{t}=$ luas daerah yang dicapai

$n_{1}=$ banyak siswa pada kelas eksperimen

$n_{2}=$ banyak siswa pada kelas kontrol

$S_{1}=$ simpangan baku kelas eksperimen

$S_{2}=$ simpangan baku kelas kontrol

$X_{1}=$ rata-rata selisih skor siswa kelas eksperimen

$X_{2}=$ rata-rata selisih skor siswa kelas kontrol

dalam uji normalitas Kolmogorov-smirnov di atas jika > 0.05 maka Ha diterima (berdistribusi normal) dan jika taraf signifikan yang diperoleh $<0.05$ maka Ho ditolak (tidak berdistribusi normal). Dapat disimpulkan bahwa data berdistribusi normal. Dengan demikian, asumsi atau persyaratan sudah terpenuhi. Berdasarkan Uji Homogenitas diketahui nilai sig. Based on mean untuk variabel hasil belajara dalah sebesar 0.044 (nilai ini sama seperti uji homogenitas dengan cara yang pertama). Karena nilai Sig $0.044>0.05$ maka dapat disimpulkan bahwa varians data hasil belajar siswa pada kelas control dan eksperimen adalah sama atau homogen. Dan Uji $\mathrm{T}$ (hipotesis) dari perhitungan data yang dilakukan diketahui nilai $\mathrm{t}$ hitung $6.531>\mathrm{t}$ tabel 2.055 maka sebagaimana pengambilan keputusan dapat disimpulkan bahwa Ho ditolakdan Ha diterima. Sehingga dapat disimpulkan bahwa ada pengaruh Model Discovery Learning Terhadap Hasil Belajar Siswa Pada Tema 8 Daerah Tempat Tinggalku Kelas IV SD Negeri 091363 Huta Tinggir Tahun Pelajaran 2019/2020.

Berdasarkan data yang diperoleh dari penelitian SD Negeri 091363 Huta Tinggir dapat dikatakan bahwa ada pengaruh model discovery learning terhadap hasil belajar siswa karena siswa dapat memberikan pendapatnya masing-masing sehingga tidak hanya berpusat pada guru. Berdasarkan penelitian SD Negeri 091363 Huta Tinggir Tahun Pembelajaran 2019/2020 dan hasil 


\section{PRIMARY : JURNAL PENDIDIKAN GURU SEKOLAH DASAR}

VOLUME 9 NOMOR 6 DESEMBER 2020

ISSN: 2303-1514 | E-ISSN: 2598-5949

yang diperoleh dari data penelitian, yaitu penulis menyimpulkan bahwa ada pengaruh signifikan dari model Descovery Learning Terhadap Hasil Belajar
Siswa Kelas IV SD Negeri 091363 Huta Tinggir Tahun Pembeajaran 2019/2020.

\section{SIMPULAN DAN REKOMENDASI}

Berdasarkan hasil analisis data dan pengujian hipotesis serta pembahasan, maka dapat ditarik kesimpulan sebagai berikut:

1. Nilai rata-rata hasil belajar pada tema 8 subtema 2 pembelajaran 1 dan pembelajaran 2 siswa kelas IV SD Negeri 091363 Huta Tinggir tahun pembelajaran 2019/2020 tampa menggunakan model Discovery Learning adalah 67.1 berada dalam kategori cukup.

2. Nilai rata-rata hasil belajar pada tema 8 subtema 2 pembelajaran 1 dan pembelajaran 2

\section{DAFTAR PUSTAKA}

Arikunto. (2017). Prosedur Penelitian Suatu Pendekatan Praktik. Jakarta: PT Rineka Cipta.

Aunurrahman. (2012). Belajar dan Pembelajaran. Bandung: Penerbit Alfabeta.

Cahyo, A. N. (2018). Panduan Aplikasi Teori-teori Belajar Mengajar Teraktual dan Terpopuler. Jogjakarta: DIVA Press.

Didit, P. (2017). Pengaruh Penggunan Discovery Learning Terhadap Hasil Belajar IPS Pada Pembelajaran Terpadu Kelas IV SD Negeri I Patoman Tahun Ajaran (2016/2017). Skripsi.

Dwi, R. (2016). Penerapan Model Pembelajaran Discovery Learning Telah Dilakukan Oleh Para Ahli Peneliti. Jurnal Penelitian Pendidikan Dasar. Vol.2 No.1

Firosalia, K. (2016). Penerapan Model Pembelajaran Discovery Learning Telah Dilakukan Oleh Para Ahli Peneliti. Jurnal Penelitian Pendidikan Dasar. Vol.2 No.1

Hamalik, O. (2013). Proses Belajar Mengajar. Jakarta: PT Bumi Aksara.

Istirani \& Pulungan, I. (2017). Ensiklopedia Pendidikan. Medan: Mediapersada.

Karlina, W. (2019). Pengaruh Model Discovery Learning terhadap Keterampilan Berpikir

siswa kelas IV SD Negeri 091363 Huta Tinggir tahun pembelajaran 2019/2020 dengan menggunakan model Discovery Learning adalah 81.19 berada dalam kategori sangat baik.

3. Hasil belajar siswa dengan menggunakan model Discovery Learning berpengaruh signifikan terhadap hasil belajar.

Berdasarkan hasil uji hipotesis maka dapat disimpulkan bahwa $t_{\text {hitung }}$ diperoleh lebih besar dari $t_{\text {tabel }}$ yaitu $6.531>2.055$ artinya hipotesis nilai $(\mathrm{Ho})$ ditolak dan hipotesis alternative (Ha) diterima.

Kritis Siswa Sekolah Dasar. Journal Of Primary Education . Vol.1 No.2

Kodir, A. (2018). Manajemen pembelajaran Saintifik Kurikulum 2013 Pembelajaran Berpusat Pada Siswa. Bandung.

Kurniawan, D. (2014). Pembelajaran Terpadu Tematik. Bandung; Alfabet.

Margono. (2018). Metodologi Penelitian Pendidikan. Jakarta: PT Rineka Cipta.

Prastowo, A. (2014). Pengembangan Bahan Ajar Tematik. Jakarta.

Purwanto. (2017). Evaluasi Hasil Belajar. Yogyakarta.

Rosdiana. (2017). Pengaruh Penggunaan Model Discovery Learning Terhadap Efektivitas dan Hasil Belajar Siswa. Jurnal Pendidikan. Vol.2 No.8.

Sardiman. (2017). Intraksi \& Motivasi Belajar Mengajar. Jakarta: PT Raja Granfindo Persada.

Septa, Anggra. (2018). Pengaruh Model Pembelajaran Discovery Learning Terhadap Hasil Belajar Tematik Pada Siswa Kelas IV SD Negeri 1 Sidodadi Tahun Ajaran (2017/2018). Skripsi

Sinaga, R. (2016). School Education Journal Pgsd Fib Unimed.Vol.4 No. 1 
Slameto. (2017). Belajar dan Faktor-faktor yang Mempengaruhi. Jakarta: PT Asdi Mahasatya.

Sugiyono. (2017). Metode Penelitian Kombinasi. Bandung: Penerbit Alfabeta.

Sugiyono. (2018). Metode Penelitian Kuantitatif, Kualitatif, dan R\&D. Bandung: Penerbit Alfabeta.

Susanto, A. (2012). Teori Belajar Pembelajaran. Jakarta: Prenadamedia Group.

Widiasworo, E. (2018). Strategi \& Metode Mengajar Siswa di luar Kelas ( Outdoor Learning): Yogyakarta .

Putrayasa. (2014). Jurnal Mimbar PGSD Universitas Pendidikan Genesh Jurusan PGSD vol.2 No.1

Arikunto. (2017). Prosedur Penelitian Suatu Pendekatan Praktik. Jakarta: PT Rineka Cipta.

Aunurrahman. (2012). Belajar dan Pembelajaran. Bandung: Penerbit Alfabeta.

Cahyo, A. N. (2018). Panduan Aplikasi Teori-teori Belajar Mengajar Teraktual dan Terpopuler. Jogjakarta: DIVA Press.

Didit, P. (2017). Pengaruh Penggunan Discovery Learning Terhadap Hasil Belajar IPS Pada Pembelajaran Terpadu Kelas IV SD Negeri I Patoman Tahun Ajaran (2016/2017). Skripsi.

Dwi, R. (2016). Penerapan Model Pembelajaran Discovery Learning Telah Dilakukan Oleh Para Ahli Peneliti. Jurnal Penelitian Pendidikan Dasar. Vol.2 No.1.

Firosalia, K. (2016). Penerapan Model Pembelajaran Discovery Learning Telah Dilakukan Oleh Para Ahli Peneliti. Jurnal Penelitian Pendidikan Dasar. Vol.2 No.1.

Hamalik, O. (2013). Proses Belajar Mengajar. Jakarta: PT Bumi Aksara.

Istirani \& Pulungan, I. (2017). Ensiklopedia Pendidikan. Mediapersada, Medan.

Karlina, W. (2019). Pengaruh Model Discovery Learning terhadap Keterampilan Berpikir Kritis Siswa Sekolah Dasar. Journal Of Primary Education . Vol.1 No.2.

Kodir, A. (2018). Manajemen pembelajaran Saintifik Kurikulum 2013 Pembelajaran Berpusat Pada Siswa. Bandung.
Kurniawan, D. (2014). Pembelajaran Terpadu Tematik. Bandung; Alfabet.

Margono. (2018). Metodologi Penelitian Pendidikan. Jakarta: PT Rineka Cipta.

Prastowo, A. (2014). Pengembangan Bahan Ajar Tematik. Jakarta.

Purwanto. (2017). Evaluasi Hasil Belajar. Yogyakarta.

Rosdiana. (2017). Pengaruh Penggunaan Model Discovery Learning Terhadap Efektivitas dan Hasil Belajar Siswa. Jurnal Pendidikan. Vol.2 No.8.

Sardiman. (2017). Intraksi \& Motivasi Belajar Mengajar. Jakarta: PT Raja Granfindo Persada.

Septa, Anggra. (2018). Pengaruh Model Pembelajaran Discovery Learning Terhadap Hasil Belajar Tematik Pada Siswa Kelas IV SD Negeri 1 Sidodadi Tahun Ajaran (2017/2018). Skripsi

Sinaga, R. (2016). School Education Journal Pgsd Fib Unimed.Vol.4 No. 1

Slameto. (2017). Belajar dan Faktor-faktor yang Mempengaruhi. Jakarta: PT Asdi Mahasatya.

Sugiyono. (2017). Metode Penelitian Kombinasi. Bandung: penerbit Alfabeta.

Sugiyono. (2018). Metode Penelitian Kuantitatif, Kualitatif, dan R\&D. Bandung: Penerbit Alfabeta.

Susanto, A. (2012). Teori Belajar Pembelajaran. Jakarta: Prenadamedia Group.

Widiasworo, E. (2018). Strategi \& Metode Mengajar Siswa di luar Kelas ( Outdoor Learning): Yogyakarta .

Mariza, F. (2015). Jurnal Inpafi. Vol.3 No.2

Putrayasa. (2014). Jurnal Mimbar PGSD Universitas Pendidikan Genesh Jurusan PGSD vol.2 No.1 